\title{
Elevated Serum Midkine Levels in Severe Acute Respiratory Syndrome Coronavirus 2 (SARS-CoV-2) Infected Patients
}

\section{Sema Ketenci}

Istanbul Atlas University

\section{Uygar Kalaycı}

Istanbul Atlas University

\section{Bağnu Dündar}

Istanbul Atlas University

Recep Duranay

Istanbul Atlas University

A.Şükrü Aynacıoğlu ( $\nabla$ sukru.aynacioglu@atlas.edu.tr)

Istanbul Atlas University https://orcid.org/0000-0003-4857-5965

\section{Research Article}

Keywords: Midkine, inflammation, SARS-CoV-2, COVID-19

Posted Date: December 8th, 2021

DOI: https://doi.org/10.21203/rs.3.rs-1108406/v1

License: (c) (1) This work is licensed under a Creative Commons Attribution 4.0 International License. Read Full License 


\section{Abstract}

The coronavirus disease-2019 (COVID-19) pandemic has caused important health, economic, social, and cultural problems worldwide. Recent findings demonstrate an excessive cytokine release during the disease development, especially in the seriously life-threatening form of COVID-19. Among other chemokines and cytokines that are released in high amounts at the infection site of severe acute respiratory syndrome coronavirus 2 (SARS-CoV-2), midkine (MK), which is an important pro-inflammatory growth factor/ cytokine, can be also overexpressed and contribute to the pathophysiological process in patients infected with SARS-CoV-2. Serum was collected from 87 intensive care unit (ICU) patients that are COVID-19 positive and 50 healthy volunteers in the control group with a negative PCR test and without disease symptoms. Circulating MK concentration was measured by enzyme-linked immunosorbent assay (ELISA) using a commercial human MK kit. COVID-19 patients had a significantly higher serum MK concentration compared to non-COVID-19 control subjects $(1892.8 \pm 1615.8 \mathrm{pg} / \mathrm{ml}$ versus $680.7 \pm 907.6 \mathrm{pg} / \mathrm{ml}$, respectively; $P<0.001)$. The cut-off MK concentration was $716.7 \mathrm{pg} / \mathrm{ml}$, with the sensitivity and specificity of $75.9 \%$ and $76.0 \%$, respectively. The area under the receiver operating characteristic $(R O C)$ curve $\left(A \cup C_{R O C}\right)$ of $M K$ was $=.827$. Our findings showed that circulating MK levels are significantly increased in SARS-CoV-2 infected patients. We suggest that MK is involved in the pathogenesis of COVID-19 and may be a part of hypercytokinaemia. Therefore, MK may serve as a supporting inflammatory marker in the diagnosis of COVID-19 and by blocking MK actions or its targets may attenuate the inflammatory process and the severity of the disease.

\section{Introduction}

The severe acute respiratory syndrome coronavirus 2 (SARS-CoV-2), by causing systemic inflammation, multi-organ damage, and even death, is responsible for coronavirus disease 2019 (COVID-19), which initiate many terrible problems worldwide nearly two years [1]. As described for other SARS infections that occurred in the near past, the primary pathophysiologic infection process begins with the binding of SARS-CoV-2 to angiotensin-converting enzyme 2 (ACE2) that serves as a receptor for the virus, followed by the internalization of the virus-ACE2 complex into the cell and continued with the replication of SARSCoV-2, which in turn triggers the pathological reactions related to COVID-19 [2-4]. The symptomatology of patients infected with SARS-CoV-2 varies widely, ranging from asymptomatic or mild symptom states to life-threatening conditions such as pneumonia, pulmonary edema, respiratory failure, vascular hyperpermeability, acute respiratory distress syndrome (ARDS), septic shock, multiple organ failure and even death $[5,6]$. In such seriously conditions, the production of pro-inflammatory chemokines and cytokines, including tumor necrosis factor alpha (TNF-a), interleukin-1 $\beta$ (IL-1 $\beta$ ), interleukin-6 (IL-6) and interferongamma (IFNY), are abnormally increased that result in a "cytokine storm", which generate COVID-19 symptoms (fever, headaches, dizziness, etc.) and cause diffuse alveolar damage [5, 7-9]. Some of these mediators are also involved in the development of life-threatening pathologies such as cardiomyopathy, lung injury, and septic shock [10,11]. Furthermore, other factors such as hypoxia, oxidative stress, and 
neutrophil extracellular traps (NETs) released from neutrophils also contribute to cytokine storm-related events [12-14].

Midkine (MK), a heparin-binding growth factor and cytokine, is highly expressed during embryogenesis, regresses to relatively low levels in healthy adults, and overexpressed once again in certain pathologies, including inflammatory diseases and malignancies [15-17]. It contributes to the growth and repair, survival, reproduction, and differentiation of various cells and has chemotactic activity as well as proinflammatory actions $[18,19]$. MK promotes inflammatory processes in autoimmune and inflammatory diseases via its chemotactic action, resulting in the accumulation of inflammatory cells, which in turn aggravate the pathological inflammatory response [20]. Several studies showed a close interaction between MK and other chemokines and cytokines, which are key mediators in SARS-CoV-2 infection [5, 7-9, 21]. For example, the expression of MK is induced by TNFa, an important component of cytokine storm in COVID-19, and vice versa [22]. In addition, there is growing evidence that MK is potentially involved in the development of pulmonary fibrosis, one of the serious outcomes in SARS-CoV-2 infection, by regulating inflammatory cell migration into the lung and expression of TNF-a and other mediators [23, 24]. Considering all these data, in a recent article, we tried to explain the possible mechanisms by which MK may be involved in the pathogenesis of SARS-CoV-2 infection [25]. Therefore, to find out whether MK is involved in the inflammatory and other pathophysiological processes associated with SARS-CoV-2 infection, we analyzed circulating MK concentration in hospitalized COVID-19 patients and compared it to non-infected control subjects.

\section{Material And Methods}

\section{Study population}

Fifty-seven participants were recruited. A total of 87 patients diagnosed with COVID-19 who were hospitalized in the intensive care unit (ICU) of Istanbul Atlas University Medicine Hospital and 50 healthy volunteers with negative COVID-19 PCR test and no symptoms of disease were included into the study. COVID-19 patients with liver dysfunction, rheumatoid arthritis, and other inflammatory diseases were evaluated in terms of concomitant disease. Informed consent was obtained from all patients and healthy volunteers. All participants underwent a standard clinical evaluation that included medical history and physical examination. Routine biochemical tests were performed in all ICU patients. Healthy volunteers were followed for 14 days to rule out the possibility of later contracting COVID-19 disease. None of them had a positive PCR test and no signs of COVID-19 after this period.

\section{Analytical methods}

Serum was obtained from $5 \mathrm{ml}$ venous blood samples of COVID-19 patients and healthy controls, Serum samples were taken and stored at $-80^{\circ} \mathrm{C}$ until measuring MK levels using the ELISA assay. To determine the serum concentration of MK in the study population, we used a commercially available human MK ELISA kit (Boster CA, USA) according to the manufacturer's instructions. Briefly described, microtiter wells precoated with anti-human MK antibodies were incubated with the patient serum. After washing, a biotin- 
labeled anti-human MK antibody was added and the plates were incubated for 1 hour with captured MK. After thorough washing, streptavidin horseradish peroxidase conjugate was added to convert the substrate $\mathrm{H} 2 \mathrm{O} 2$-tetramethylbenzidine. The absorption of the solution can be analyzed photometrically at $450 \mathrm{~nm}$ (OD450) wavelengths in the microplate reader (Dynatech MR 500). To measure the exact concentration of the analysts in the liquid phase, a calibration curve was plotted based on samples with known concentrations. MK concentration is given in $\mathrm{pg} / \mathrm{mL}$.

\section{Statistical analysis}

All data were analyzed by IBM SPSS Statistics for Windows 10, version 25.0. The non-normality of the data distribution was determined by the Sahpiro-Wilk test, Kolmogorov-Smirnov and histograms.

Parametric values of the patients were expressed as numbers and percentages and categorical values were analyzed with a Chi-square test. MK concentration values of patients and controls were presented as mean and standard deviation (SD) or median values and an interquartile range of $25-75 \%$. MannWhitney U test was used to test non-parametric values. In COVID-19 patients, to observe the effect of MK concentration values - to determine the distinction between severe and mild COVID-19 groups, to see the effect of comorbidity on the MK levels of patients, the increase in the MK level in patients with varying thresholds was calculated. For this calculation, the receiver-operating characteristic curve (ROC) were generated and the area under the curve (AUC) was calculated. Where appropriate, $95 \% \mathrm{Cl}$ were also calculated. The $95 \% \mathrm{Cl}$ were calculated anytime convenient, and two-tailed $p$-value $p<0,05$ was considered statistically significant.

\section{Results}

From the 87 COVID-19 patients and 50 non-COVID-19 subjects, 37 (42.5\%) and 37 (74\%) were female and $50(57.5 \%)$ and $13(26 \%)$ were male, respectively. While 16 of 50 males and 12 of 37 female patients hospitalized in the ICU died, 34 male and 25 female patients were discharged. The mean age of deceased and discharged COVID-19 patients was $71.3 \pm 12.1$ and $57.15 \pm 11.2$, respectively, which the difference was as expected statistically significant $(P<0.001)$. The mean duration of hospital stay in the ICU was $9.1 \pm$ 6.3 days who were died and $10.2 \pm 6.6$ days who were discharged $(P>0.05)$. Twenty-six of the deceased $(93 \%)$ and $9(15 \%)$ of the discharged patient had at least 2 comorbidities (Table 2$)$. 
Table 2

Demographic and biologic characteristic of the COVID-19 patients

\begin{tabular}{|c|c|c|c|c|}
\hline & $\begin{array}{l}\text { Total } \\
(n=87)\end{array}$ & $\begin{array}{l}\text { Survivor } \\
(n=59)\end{array}$ & $\begin{array}{l}\text { Non-survivor } \\
(n=28)\end{array}$ & $P$ \\
\hline Age, years* & $64.2 \pm 11.5$ & $57.15 \pm 11$ & $71.3 \pm 12$ & $<0.01$ \\
\hline Sex, female/male & $37 / 50$ & $25 / 34$ & $12 / 16$ & 0.002 \\
\hline Stay in the ICU, days* & $9.1 \pm 6.3$ & $9 \pm 6.2$ & $9.2 \pm 6.6$ & 0.018 \\
\hline More than one co-morbidity & 35 & 9 & 26 & 0.001 \\
\hline Glucose (mg/dl) & $70(80 \%)$ & $48(81 \%)$ & $26(92 \%)$ & $<0.01$ \\
\hline$>126$ & $17(20 \%)$ & $11(19 \%)$ & $2(8 \%)$ & \\
\hline \multicolumn{5}{|l|}{$<126$} \\
\hline $\mathrm{CRP}(\mathrm{mg} / \mathrm{L})$ & $84(96 \%)$ & $56(94 \%)$ & $28(100 \%)$ & $<0.01$ \\
\hline$>5$ & $3(4 \%)$ & $3(6 \%)$ & 0 & \\
\hline \multicolumn{5}{|l|}{$<5$} \\
\hline NLR (cells/ $\mu \mathrm{l})$ & $62(71 \%)$ & $50(84 \%)$ & $25(89 \%)$ & $<0.01$ \\
\hline$>4.75$ & $15(29 \%)$ & $9(16 \%)$ & $3(11 \%)$ & \\
\hline \multicolumn{5}{|l|}{$<4.75$} \\
\hline D-dimer (mg/L) & 77 (88\%) & $50(84 \%)$ & $27(96 \%)$ & $<0.01$ \\
\hline$>0.55$ & $10(12 \%)$ & $9(16 \%)$ & $1(4 \%)$ & \\
\hline \multicolumn{5}{|l|}{$<0.55$} \\
\hline РСТ (ng/ml) & $74(85 \%)$ & $49(83 \%)$ & $22(78 \%)$ & $<0.01$ \\
\hline$>0.5$ & $13(15 \%)$ & $10(17 \%)$ & $6(22 \%)$ & \\
\hline \multicolumn{5}{|l|}{$<0.5$} \\
\hline * Data are presented as $\mathrm{m}$ & SD & & & \\
\hline
\end{tabular}

The mean serum MK concentration was $1892.8 \pm 1615.8 \mathrm{pg} / \mathrm{ml}$ versus $680.7 \pm 907.6 \mathrm{pg} / \mathrm{ml}$ in COVID-19 patients and non-COVID-19 controls, respectively (Table 1, Figure 1). Serum MK concentration was approximately 2.8 times higher in COVID-19 patients than non-COVID controls $(P<0.001)$. The area under the ROC curve (AUCROC) of MK was 0.827 with the $95 \%$ confidence interval $(C I) 0.751-0.904(P<0.001)$. The cut-off concentration of MK was $716.7 \mathrm{pg} / \mathrm{ml}$. The sensitivity and specificity of serum MK concentration in predicting COVID-19 were $75.9 \%$ and $76.0 \%$. respectively (Figure 2 ). $77 \%$ of all patients with COVID-19 and $13 \%$ of the control group are above the cut-off point and vice versa. No statistically 
significant difference was detected between deceased patients and discharged patients in regard of serum MK concentration (1913.9 \pm 1588.1 versus $2014.9 \pm 1629.8)$.

Table 1

Comparision of serum MK concentration between COVID-19 patients and nonCOVID-19 controls.

\begin{tabular}{|llll|}
\hline & Cases $(\mathbf{n}=\mathbf{8 7})$ & Controls $(\mathbf{n}=50)$ & P value \\
\hline Mean serum MK concentration & $1892.8 \pm 1615.8$ & $680.7 \pm 907.6$ & $<0.001$ \\
$(\mathrm{pg} / \mathrm{mL} \pm \mathrm{SD})$ & $(392.6-5595.4)$ & $(12.2-3414.1)$ & \\
\hline Median $(\mathrm{pg} / \mathrm{mL})$ & 1231.4 & 336.6 & $<0.001$ \\
\hline
\end{tabular}

The values of the main prognostic biomarkers that we have analyzed were elevated in all of COVID-19 patients. Furthermore. the mean levels of glucose. CRP, NLR, d-dimer, procalcitonin, ferritin and IL-6 were significantly higher in deceased patients compared to discharged patients (Table 2).

\section{Discussion}

To the best of our knowledge, this is the first investigation that analyzed the relationship between MK and COVID-19. Our findings showed that serum MK concentration is approximately 2,8 times higher in SARSCoV-2 infected patients than non-infected volunteers. Several pathophysiological changes may be responsible for this elevation of circulating MK levels in SARS-CoV-2 infected COVID-19 patients which will be discussed below.

The binding of SARS-CoV-2 to pulmonary angiotensin-converting enzyme 2 (ACE2) has two major consequences. Firstly, monocytes recruited into the alveolar space secretes pro-inflammatory cytokines, recruited macrophages releases also cytokines and chemokines that augmented capillary permeability, pulmonary edema and followed by neutrophil recruitment. Secondly, the expression of ACE2 is downregulated by SARS-CoV-2, causing over-activation of renin-angiotensin-system (RAS) that results in increased pulmonary vasoconstriction, edema, hypoxia, and lung damage in COVID-19 patients [3, 4]. In addition to releasing pro-inflammatory mediators, increased neutrophil invasion leads to the release of neutrophil extracellular traps (NETs) that are intracellular contents such as DNA, histones, and proteins. Several studies showed that this process, called NETosis, is closely associated with COVID-19 [14, 26]. The excessive neutrophil degranulation precipitate lung injury and damage the alveolar-capillary barrier. Furthermore, NETosis is associated with increased levels of intracellular reactive oxygen species (ROS) of neutrophils. Excessive ROS production can lead to alveolar damage and red blood dysfunction that contribute to hypoxic respiratory failure in COVID-19 [27, 28].

Although, some studies proposed a protective effect of MK, such as promoting repair of the nervous system after injury and protective action against ischemia/reperfusion injury in the heart, some others are known as harmful including, carcinogenesis, chemo-resistance, and promoting inflammation $[18,20,30$, 
31]. MK has strong pro-inflammatory characteristics, causing macrophage and neutrophil recruitment to the inflamed region and interact with other chemokines and cytokines, particularly TNFa and ILs, that are closely associated with the development of SARS-CoV-2 infection [32]. Furthermore, MK plays an important role in mediating and generating enhancement of fibrinolytic activity, which is crucial in the initial stage of inflammatory responses of various pathologies [18,33]. Recently, Weckbach et al. showed that during myocarditis MK promotes, via the low-density lipoprotein receptor-related protein 1 , infiltration of polymorphonuclear neutrophils into the myocardium and contribute to NETosis, which is detrimental for patients with chronic inflammatory cardiomyopathy. Therefore, they suggest that inhibition of MK or NETs could have beneficial effects in treating myocarditis [34]. MK influences the RAS as well [35]. In an animal study, Hobo et al. showed that the expression of MK was induced in the lung endothelium of micro-vessels and alveolar-capillary endothelial cells by oxidative stress and upregulated by ACE, which generates Ang II from Ang I, followed by an induction of NADPH oxidase (Nox) expression by Ang II that in turn initiates ROS production, and subsequently MK and ACE expression. In the context of COVID-19, which uses the ACE2 receptor for its clinical manifestations, MK activates ACE, leading to higher concentrations of Ang II that impaired functions of the alveoli [36]. On the other hand, SARS-CoV-2 invasion itself causes fluid accumulation in the alveoli, the effectiveness of air exchange decreases dramatically, resulting in hypoxia, hypoxemia, and subsequently ARDS. Hypoxia, a powerful inflammatory stimulant, is induced in inflammatory conditions, leading to cytokine storm, inflammation, and other molecular events that are important components of SARS-CoV-2 infection [37]. One of the pathophysiological processes that is triggered by hypoxia is the induction of hypoxia-inducible factor-1a (HIF-1a). Under normal pressure of oxygen in bloodstream, the expression of HIF-1a caused by phagocytic cells, such as neutrophils and macrophages, is low. However, in infection sites, including SARS-CoV-2, they increase HIF-1a expression, which in turn stimulates the expression of several proinflammatory cytokines [38]. Owing to its pro-inflammatory properties, it has been suggested that inhibition of HIF-1a activity can reduce the SARS-CoV-2 related inflammation and relieves the severity of COVID-19 [39, 40]. In a mice model, it has been shown that MK expression was markedly increased in the lungs during exposure to hypoxia via binding of HIF1-a to hypoxia-responsive elements located in the MK promoter [41]. Considering the interplay between MK, hypoxia and HIF1-a in pulmonary tissue, it seems possible that they reinforce each other's pathophysiological actions, as well as in SARS-CoV-2 infection.

An important case of SARS-CoV-2 infection is the development of ARDS, which can cause severe lung injury. Several studies demonstrated that MK is closely involved in the pathogenesis of ARDS. Zhang et al. showed that exposure to a mechanical stretch of lung epithelial cells led to an epithelial-mesenchymal transition profile associated with increased expression of ACE, which was attenuated by silencing MK in mice [42]. Furthermore, they found that the plasma concentration of MK was significantly elevated in patients with ARDS. Similarly, in idiopathic pulmonary fibrosis patients, the serum MK level was found higher compared to healthy subjects, supporting the role of MK in the development of ARDS. In the same study, it has been proposed that MK may participate to the progression of pulmonary fibrosis, mainly by regulating inflammatory cell migration into the lung and augmenting transforming growth factor $\beta$ (TGF- 
$\beta)$ expression, which may be primarily responsible for the lung fibrosis at the end stage of COVID-19 [24, 43].

\section{Conclusions}

The results of our study demonstrated an approximately 2.8-fold higher serum concentration of MK in a cohort of COVID-19 patients compared to non-infected subjects. Since MK is significantly upregulated upon exposure to various harmful stimuli such as inflammation, it is likely to accompany the cytokine attack that occurs in SARS-CoV-2 infection. Thus, among treatment strategies targeting cytokines (e.g. inhibition of TNFa, TGF- $\beta$ or IL-6), drugs that suppress additionally the generation or action of MK may also contribute to COVID-19 treatment.

\section{Declarations}

\section{Authors' contributions}

AŞA was the guarantor of the submission. SK and AŞA designed the study. MUK and BD enrolled the patients

and collected the data. RD performed the statistical analysis of this study. SK and AŞA wrote the manuscript. All authors read and approved the final version of the manuscript.

\section{Funding}

There is no funding while preparing this manuscript.

\section{Availability of data and material}

The data that support the findings of this study are available from the corresponding author upon reasonable request.

\section{Conflict of interest}

The authors declare no conflict of interest.

\section{Ethical approval}

This study was performed in accordance with the Declaration of Helsinki and was approved by The Republic of Turkey Ministry of Health (Number: 2020-10-23T23_59_00) and Local Ethics Committee of Istanbul Atlas University (Number: E-22686390-050.01.04-4187). The authors obtained informed consent from all patients.

\section{Consent to participate}


Informed consent was obtained from all individual participants included in the study.

\section{Consent for publication}

Consents were obtained from all authors before submission.

\section{References}

1. Zhu N, Zhang D, Wang W, et al, A novel coronavirus from patients with pneumonia in China, 2019. N Engl J Med. 2020;382(8):727-733. https://doi:10.1056/NEJMoa2001017

2. Li W, Moore MJ, Vasilieva N, et al. Angiotensin-converting enzyme 2 is a functional receptor for the SARS coronavirus. Nature. 2003;426(6965):450-454. https://doi:10.1038/nature02145

3. Wan Y, Shang J, Graham R, Baric RS, Li F. Receptor recognition by the novel coronavirus from Wuhan: an analysis based on decade-long structural studies of SARS coronavirus. J Virol. 2020;94(7), e00127-20. https://doi:10.1128/JVI.00127-20

4. Hoffmann M, Kleine-Weber $\mathrm{H}$, Schroeder $\mathrm{S}$, et al. SARS-CoV-2 cell entry depends on ACE2 and TMPRSS2 and is blocked by a clinically proven protease inhibitor. Cell. 2020;181(2):271-280. https://doi.org/10.1016/j.cell.2020.02.052

5. Huang C, Wang Y, Li X, et al. Clinical features of patients infected with 2019 novel coronavirus in Wuhan, China. Lancet. 2020;395(10223):497-506. https://doi:10.1016/S0140-6736(20)30183-5

6. Williamson EJ, Walker AJ, Bhaskaran K, et al. Factors associated with COVID-19-related death using OpenSAFELY. Nature. 2020;584(7821), 430-436. https://doi:10.1038/s41586-020-2521-4

7. Channappanavar R, Perlman S. Pathogenic human coronavirus infections: causes and consequences of cytokine storm and immunopathology. Semin Immunopathol. 2017;39(5):529-539. https://doi:10.1007/s00281-017-0629-x

8. Gao YM, Xu G, Wang B, Liu BC. Cytokine storm syndrome in coronavirus disease 2019: A narrative review. J Intern Med. 2021;289(2):147-161. https://doi:10.1111/joim.13144

9. Ye Q, Wang B, Mao J. The pathogenesis and treatment of the 'Cytokine Storm' in COVID-19. J Infect. 2020;80(6):607-613. https://doi:10.1016/j.jinf.2020.03.037

10. Li N, Zhu L, Sun L, Shao G. The effects of novel coronavirus (SARS-CoV-2) infection on cardiovascular diseases and cardiopulmonary injuries. Stem Cell Res.2021;51:102168. https://doi.org/10.21037/tlcr-21-663 
11. Guan WJ, Ni ZY, Hu Y, et al. Clinical characteristics of coronavirus disease 2019 in China. N Engl J Med. 2020;382(18):1708-1720. https://doi:10.1056/NEJMoa2002032

12. Lee KY. Pneumonia, acute respiratory distress syndrome, and early immune-modulator therapy. Int $\mathrm{J}$ Mol Sci. 2017;18(2):388. https://doi:10.3390/ijms18020388

13. Zuo Y, Yalavarthi S, Shi H, et al. Neutrophil extracellular traps in COVID-19. JCI Insight. 2020;5(11):e138999. https://doi:10.1172/jci.insight.138999

14. Veras FP, Pontelli MC, Silva CM, et al. SARS-CoV-2-triggered neutrophil extracellular traps mediate COVID-19 pathology. J Exp Med. 2020;217(12):e20201129. https://doi:10.1084/jem.20201129

15. Kadomatsu K, Tomomura M, Muramatsu T. cDNA cloning and sequencing of a new gene intensely expressed in early differentiation stages of embryonal carcinoma cells and in mid-gestation period of mouse embryogenesis. Biochem Biophys Res Commun. 1988;151(3):1312-1318.

https://doi:10.1016/s0006-291x(88)80505-9

16. Weckbach LT, Preissner KT, Deindl E. The role of midkine in arteriogenesis, involving mechanosensing, endothelial cell proliferation, and vasodilation. Int J Mol Sci. 2018;19(9):2559. https://doi:10.3390/ijms19092559

17. Filippou PS, Karagiannis GS, Constantinidou A. Midkine (MDK) growth factor: a key player in cancer progression and a promising therapeutic target. Oncogene. 2020;39(10):2040-2054. https://doi:10.1038/s41388-019-1124-8

18. Muramatsu T. Midkine and pleiotrophin: two related proteins involved in development, survival, inflammation and tumorigenesis. J Biochem. 2002;132(3):359-371. https://doi:10.1093/oxfordjournals.jbchem.a003231

19. Muramatsu T. Midkine, a heparin-binding cytokine with multiple roles in development, repair and diseases. Proc Jpn Acad Ser B Phys Biol Sci. 2010;86(4):410-425. https://doi:10.2183/pjab.86.410

20. Takada T, Toriyama K, Muramatsu H, Song XJ, Torii S, Muramatsu T. Midkine, a retinoic acidinducible heparin-binding cytokine in inflammatory responses: chemotactic activity to neutrophils and association with inflammatory synovitis. J Biochem. 1997;122(2):453-458.

https://doi:10.1093/oxfordjournals.jbchem.a021773

21. Krzystek-Korpacka M, Diakowska D, Neubauer K, Gamian A. Circulating midkine in malignant and non-malignant colorectal diseases. Cytokine. 2013;64(1):158-164.

https://doi:10.1016/j.cyto.2013.07.008

22. Shindo $\mathrm{E}$, Nanki T, Kusunoki $\mathrm{N}$, et al, The growth factor midkine may play a pathophysiological role in rheumatoid arthritis. Mod Rheumatol. 2017;27(1):54-59.

https://doi.org/10.1080/14397595.2016.1179860

Page 10/14 
23. Zhang R, Pan Y, Fanelli V, et al. Mechanical stress and the induction of lung fibrosis via the midkine signaling pathway. Am J Respir Crit Care Med. 2015;192(3):315-323.

https://doi.org/10.1164/rccm.201412-23260C

24. Misa $\mathrm{K}$, Tanino $\mathrm{Y}$, Wang $\mathrm{X}$, et al. Involvement of midkine in the development of pulmonary fibrosis. Physiol Rep. 2017;5(16):e13383. https://doi.org/10.14814/phy2.13383

25. Ketenci S, Aynacıoğlu AŞ. The growth factor/cytokine midkine may participate in cytokine storm and contribute to the pathogenesis of severe acute respiratory syndrome coronavirus 2-infected patients. Egypt J Bronchol. 2021;15(1), 1-6. https://doi.org/10.1186/s43168-021-00087-6

26. Arcanjo A, Logullo J, Menezes CCB, et al. The emerging role of neutrophil extracellular traps in severe acute respiratory syndrome coronavirus 2 (COVID-19). Sci Rep. 2020;10(1):19630. https://doi.org/10.1038/s41598-020-76781-0

27. Reshi ML, Su YC, Hong JR. RNA Viruses: ROS-Mediated Cell Death. Int J Cell Biol. 2014;2014:467452. https://doi:10.1155/2014/467452

28. Laforge $M$, Elbim C, Frère $C$, et al. Tissue damage from neutrophil-induced oxidative stress in COVID19. Nat Rev Immunol. 2020;20(9):515-516. https://doi.org/10.1038/s41577-020-0407-1

29. Yoshida Y, Sakakima H, Matsuda F, Ikutomo M. Midkine in repair of the injured nervous system. Br J Pharmacol. 2014;171(4):924-930. https://doi.org/10.1111/bph.12497

30. Horiba M, Kadomatsu K, Yasui K, et al. Midkine plays a protective role against cardiac ischemia/reperfusion injury through a reduction of apoptotic reaction. Circulation. 2006;114(16):17131720. https://doi.org/10.1161/CIRCULATIONAHA.106.632273

31. Kang HC, Kim IJ, Park HW, et al. Regulation of MDK expression in human cancer cells modulates sensitivities to various anticancer drugs: MDK overexpression confers to a multi-drug resistance. Cancer Lett. 2007;247(1):40-47. https://doi.org/10.1016/j.canlet.2006.03.017

32. Weckbach LT, Gola A, Winkelmann M, et al. The cytokine midkine supports neutrophil trafficking during acute inflammation by promoting adhesion via $\beta 2$ integrins (CD11/CD18). Blood. 2014;123(12):1887-1896. https://doi.org/10.1182/blood-2013-06-510875

33. Kojima S, Muramatsu $\mathrm{H}$, Amanuma $\mathrm{H}$, Muramatsu T. Midkine enhances fibrinolytic activity of bovine endothelial cells. J Biol Chem. 1995;270(16):9590-9596. https://doi.org/10.1074/jbc.270.16.9590

34. Weckbach LT, Grabmaier U, Uhl A, Gess S, Boehm F, Zehrer. Midkine drives cardiac inflammation by promoting neutrophil trafficking and NETosis in myocarditis. J Exp Med. 2019;216(2):350-368. https://doi.org/10.1084/jem.20181102 
35. Kadomatsu K. Midkine regulation of the renin-angiotensin system. Curr Hypertens Rep. 2010;12(2):74-79. https://doi.org/10.1007/s11906-010-0092-8

36. Hobo A, Yuzawa $Y$, Kosugi $T$, et al. The growth factor midkine regulates the renin-angiotensin system in mice. J Clin Invest. 2009;119(6):1616-1625. https://doi.org/10.1172/JCI37249

37. Eltzschig HK, Carmeliet P. Hypoxia and inflammation. N Engl J Med. 2011;364(7):656-665. https://doi.org/10.1056/NEJMra0910283

38. Jahani M, Dokaneheifard S, Mansouri K. Hypoxia: A key feature of COVID-19 launching activation of HIF-1 and cytokine storm. J Inflamm (Lond). 2020;17:33. https://doi.org/10.1186/s12950-020-00263-3

39. Serebrovska ZO, Chong EY, Serebrovska TV, Tumanovska LV, Xi L. Hypoxia, HIF-1a, and COVID-19: from pathogenic factors to potential therapeutic targets. Acta Pharmacol Sin. 2020;41(12):1539-1546. https://doi.org/10.1038/s41401-020-00554-8

40. Taniguchi-Ponciano K, Vadillo E, Mayani H, et al, (2021) Increased expression of hypoxia-induced factor $1 \mathrm{a}$ mRNA and its related genes in myeloid blood cells from critically ill COVID-19 patients. Ann Med. 2021;53(1):197-207. https://doi.org/10.1080/07853890.2020.1858234

41. Reynolds PR, Mucenski ML, Le Cras TD, Nichols WC, Whitsett JA. Midkine is regulated by hypoxia and causes pulmonary vascular remodeling. J Biol Chem. 2004;279(35):37124-37132. https://doi.org/10.1074/jbc.M405254200

42. Zhang R, Pan Y, Fanelli V, et al. Mechanical stress and the induction of lung fibrosis via the midkine signaling pathway. Am J Respir Crit Care Med. 2015;192(3):315-323.

https://doi.org/10.1164/rccm.201412-23260C

43. Chen W. A potential treatment of COVID-19 with TGF- $\beta$ blockade. Int J Biol Sci. 2020;16(11), 19541955. https://doi.org/10.7150/ijbs.46891

\section{Figures}




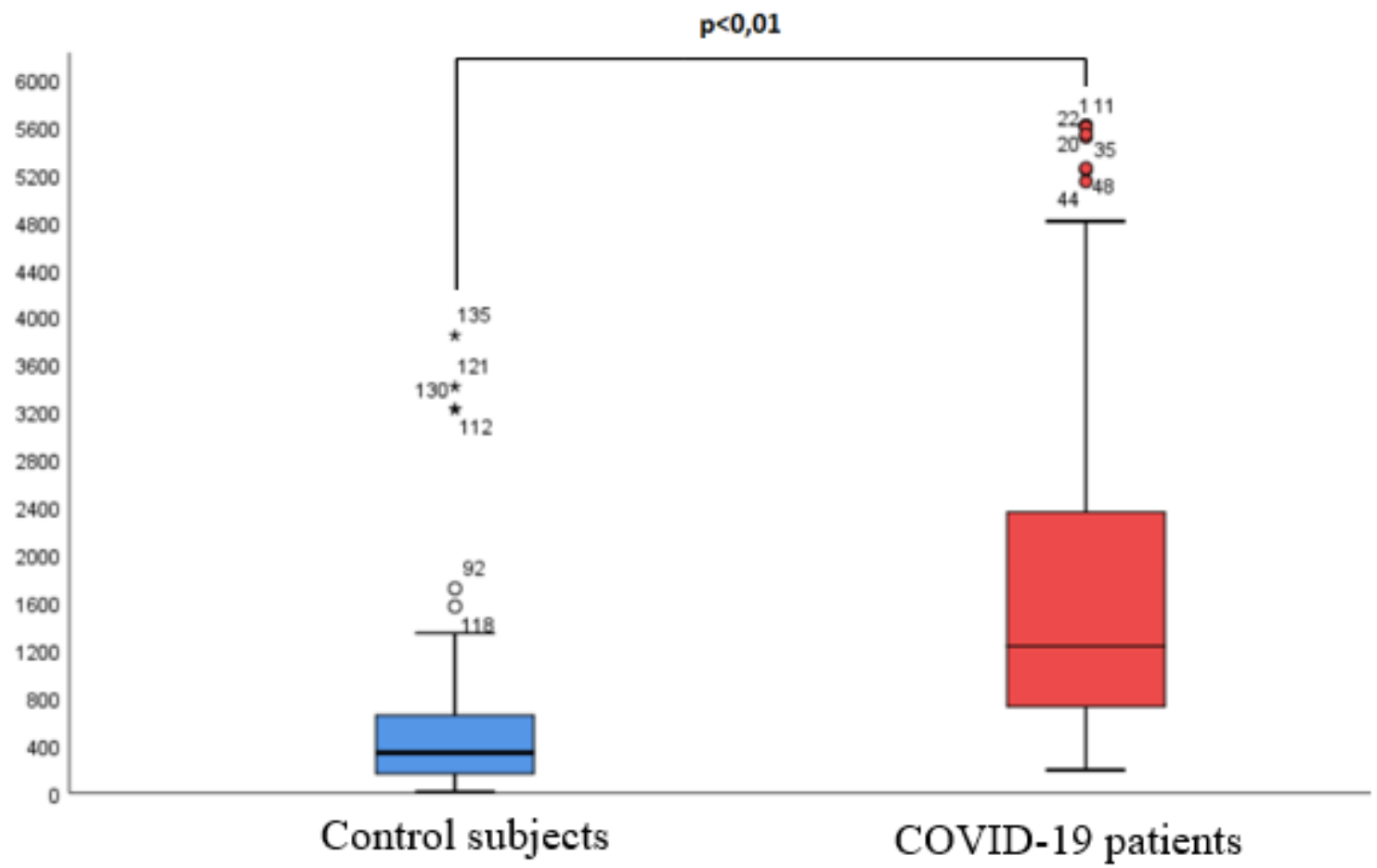

\section{Figure 1}

Distribution of MK serum concentrations in control subjects and COVID-19 patients 


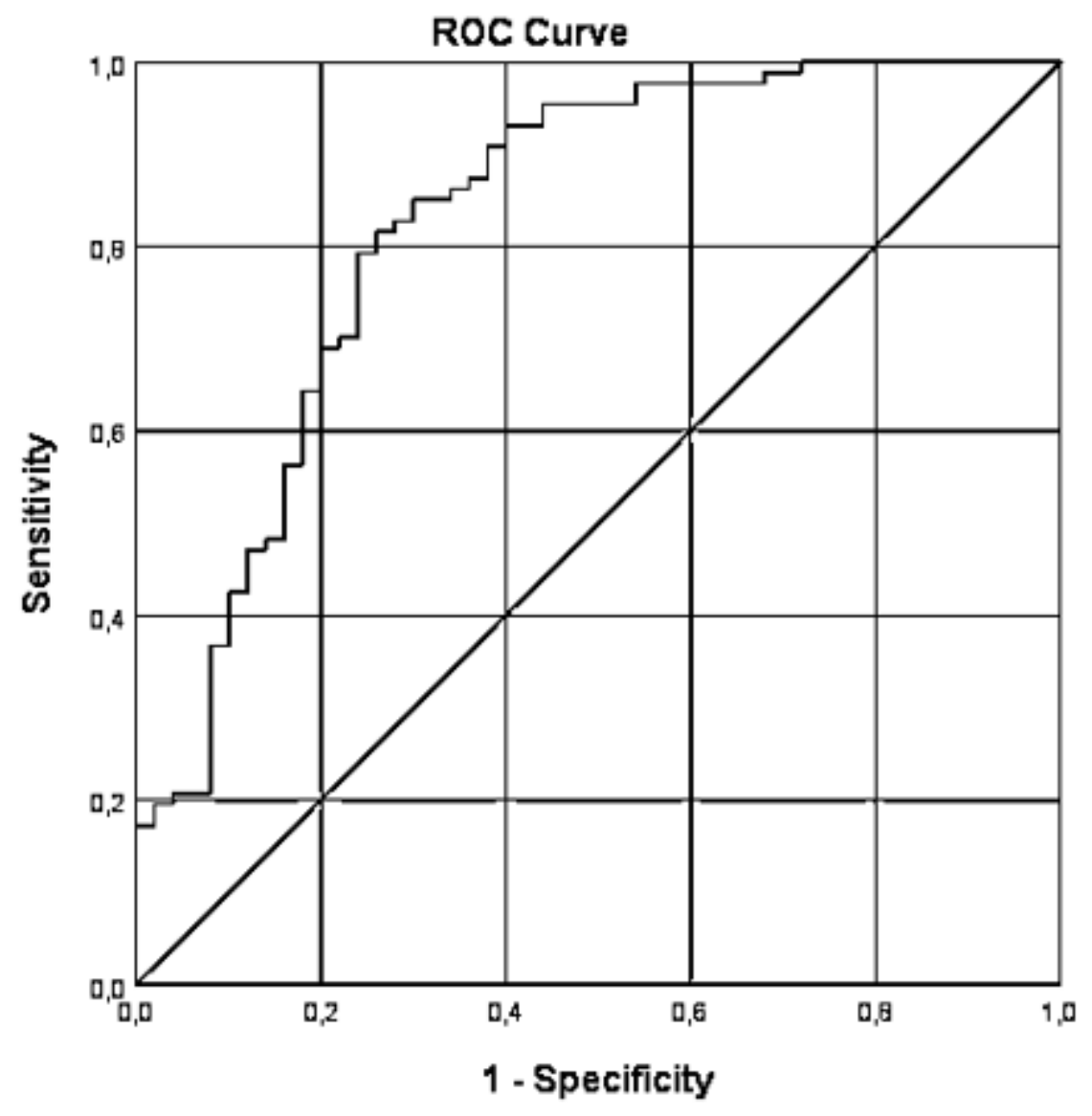

Figure 2

ROC curve demonstrating AUC $(0.827 ; 95 \% \mathrm{Cl}$ : $0.751-0.904 ; \mathrm{P}<0.001)$ for MK 